\section{Dr. Kato and Dr. Atsumi reply}

\section{To the Editor:}

We would respond to the comments by Dr. Mori ${ }^{1}$ on our recent study ${ }^{2}$. Mori enrolled 62 patients with rheumatoid arthritis (RA) who had hepatitis B surface (HBs) antigen-negative/anti-hepatitis B core-positive serology, including anti-HBs-negative serology in $30.6 \%$ (19/62). They received various disease-modifying antirheumatic drugs such as methotrexate, tacrolimus, infliximab, etanercept, and tocilizumab, but no patient developed hepatitis B virus (HBV) DNA in the sera. He concluded that the risk of reactivation of resolved HBV is low in patients with RA, even in those with anti-HBs-negative serology.

Although reactivation of resolved $\mathrm{HBV}$ is a rare complication in rheumatic diseases ${ }^{3,4,5,6,7,8,9}$, high mortality (100\% if fulminant hepatic failure develops) is of great clinical significance in this complication ${ }^{10}$, making us watchful for it in all patients with resolved HBV infection. There has been much less evidence regarding reactivation of resolved $\mathrm{HBV}$ in the field of rheumatology compared to that in oncology or transplantation. In addition, most studies regarding reactivation of resolved $\mathrm{HBV}$ in rheumatology were conducted only in patients with RA or spondyloarthropathy 3,4,5,6,7,8,9. In contrast to other studies, ours enrolled patients with various autoimmune diseases such as systemic lupus erythematosus, vasculitis syndrome, RA, polymyositis/dermatomyositis, idiopathic thrombocytopenic purpura, adult-onset Still's disease, and autoimmune hemolytic anemia, and many patients needed intensive immunosuppressive therapy such as steroid-pulse therapy in a combination with cyclophosphamide. Consequently, we found that reactivation of resolved HBV can occur during standard immunosuppressive therapy for autoimmune diseases and that anti-HBs titer was significantly lower in the patients in whom reactivation of resolved HBV occurred than in the other patients, at baseline.

Given that the patients in whom reactivation of resolved HBV developed had low anti-HBs titer at baseline, one would wonder if HBV vaccination or hepatitis B immunoglobulin would be used for the prevention of virus reactivation. Considering the low prevalence of resolved HBV reactivation in autoimmune diseases, primary prophylaxis would not be recommended. We believe, at present, that close monitoring of serum viral DNA, aspartate aminotransferase, and alanine aminotransferase could be the best management strategy, especially in patients with low anti-HBs titer who undergo aggressive immunosuppressive therapy, in treatment of autoimmune diseases.

MASARU KATO, MD, PhD; TATSUYA ATSUMI, MD, PhD, Department of Medicine II, Hokkaido University Graduate School of Medicine, Sapporo, Japan. Address correspondence to Dr. Kato;

E-mail: ktmasaru@med.hokudai.ac.jp

\section{REFERENCES}

1. Mori S. Do low titers of antibody against hepatitis B surface antigen carry a risk of viral reactivation during immunosuppressive therapy for rheumatic diseases? [letter]. J Rheumatol 2012;39:1292-3.

2. Kato M, Atsumi T, Kurita T, Odani T, Fujieda Y, Otomo K, et al. Hepatitis $\mathrm{B}$ virus reactivation by immunosuppressive therapy in patients with autoimmune diseases: Risk analysis in Hepatitis B surface antigen-negative cases. J Rheumatol 2011;38:2209-14.

3. Charpin C, Guis S, Colson P, Borentain P, Mattei JP, Alcaraz P, et al. Safety of TNF-blocking agents in rheumatic patients with serology suggesting past hepatitis B state: results from a cohort of 21 patients. Arthritis Res Ther 2009;11:R179.

4. Caporali R, Bobbio-Pallavicini F, Atzeni F, Sakellariou G, Caprioli $\mathrm{M}$, Montecucco C, et al. Safety of tumor necrosis factor alpha blockers in hepatitis B virus occult carriers (hepatitis B surface antigen negative/anti-hepatitis B core antigen positive) with rheumatic diseases. Arthritis Care Res 2010;62:749-54.

5. Vassilopoulos D, Apostolopoulou A, Hadziyannis E, Papatheodoridis GV, Manolakopoulos S, Koskinas J, et al. Long-term safety of anti-TNF treatment in patients with rheumatic diseases and chronic or resolved hepatitis B virus infection. Ann Rheum Dis 2010;69:1352-5.

6. Urata Y, Uesato R, Tanaka D, Kowatari K, Nitobe T, Nakamura Y, et al. Prevalence of reactivation of hepatitis $\mathrm{B}$ virus replication in rheumatoid arthritis patients. Mod Rheumatol 2011;21:16-23.

7. Tamori A, Koike T, Goto H, Wakitani S, Tada M, Morikawa H, et al. Prospective study of reactivation of hepatitis B virus in patients with rheumatoid arthritis who received immunosuppressive therapy: Evaluation of both HBsAg-positive and HBsAg-negative cohorts. J Gastroenterol 2011;46:556-64.

8. Lan JL, Chen YM, Hsieh TY, Chen YH, Hsieh CW, Chen DY, et al. Kinetics of viral loads and risk of hepatitis $\mathrm{B}$ virus reactivation in hepatitis B core antibody-positive rheumatoid arthritis patients undergoing anti-tumour necrosis factor alpha therapy. Ann Rheum Dis 2011;70:1719-25.

9. Mori S. Past hepatitis B virus infection in rheumatoid arthritis patients receiving biological and/or nonbiological disease-modifying antirheumatic drugs. Mod Rheumatol 2011;21:621-7.

10. Umemura T, Tanaka E, Kiyosawa K, Kumada H. Mortality secondary to fulminant hepatic failure in patients with prior resolution of hepatitis B virus infection in Japan. Clin Infect Dis 2008;47:e52-6.

J Rheumatol 2012;39:6; doi:10.3899/jrheum.120117 